\title{
Landscape ecology: an integrated science for sustainability in a changing world
}

\author{
Diane M. Pearson · Clive A. McAlpine
}

Received: 2 July 2010/Accepted: 16 July 2010/Published online: 31 August 2010

(C) Springer Science+Business Media B.V. 2010

\section{Origins of the special issue}

Human pressures on the world's landscapes are accelerating at unprecedented rates. Global climate change is compounding these pressures, making the need for sustainable landscape management and planning even more urgent. Landscape ecology is uniquely placed to address this challenge-its charter is to provide the science underpinning sustainable landscape management (Wu 2006; Musacchio 2009). The aim of this special issue is to advance landscape ecology as a science able to rise to the challenges of environmental sustainability we face this century. The special issue originated from a symposium titled 'Landscape ecology: An integrated science for sustainability in a changing world' at the 10th International Congress of Ecology (INTECOL) August 16th-21st 2009 in Brisbane, Australia. The theme of the Congress was "Ecology in a Changing Climate, Two Hemispheres, One Globe". Ecologists

D. M. Pearson ( $\square)$

School of Environmental and Life Sciences, Faculty of Education, Health and Science,

Charles Darwin University, Darwin 0909, Australia

e-mail: diane.pearson@cdu.edu.au

C. A. McAlpine

Centre for Spatial Environmental Research,

School of Geography, Planning and Environmental

Management, The University of Queensland,

St Lucia, Brisbane 4068, Australia

e-mail: c.mcalpine@uq.edu.au from both hemispheres explored how global change has impacted, and will further impact, ecosystems and their vital services to human communities. The Congress explored unique features of ecosystems in the southern and northern hemispheres, with discussions on: long term monitoring, incorporating ecological knowledge into policy, integrating indigenous knowledge into conventional science, and on communicating ecological information to a broader community. These issues arising out of the Congress are highly relevant to landscape ecology and represent a timely opportunity for this special issue of Landscape Ecology.

\section{Core themes}

The papers in this special issue originate from four continents, and consist of a mixture of conceptual, theoretical and applied approaches to addressing landscape sustainability issues. Core themes are:

How can landscape ecology contribute towards sustainability?

How can landscape ecology contribute towards sustainability is the cross-cutting theme of the special issue. Landscape ecology as a multidisciplinary and transdisciplinary science offers a way of working towards finding solutions to landscape sustainability problems (Wu 2006; Termorshuizen et al. 2007). 
Despite widespread recognition of the importance of this issue, Naveh (2007) claims the impact of landscape ecology on sustainable landscape management and planning is still limited. McAlpine et al. (2010) propose that by adopting a formal problemsolving approach, landscape ecologists can make a valuable contribution towards achieving sustainable landscapes. The approach involves making explicit the management objectives and management actions, and the system understanding required to inform sustainable landscape planning decisions. Pearson and Gorman (2010) expand on this theme by recommending a new landscape paradigm which recognizes that landscape sustainability and livelihoods are inextricably linked, especially in underdeveloped but rapidly changing regions such as northern Australia. They outline a forward looking landscape ecological paradigm, which focuses on understanding and designing the space in which biophysical, socio-cultural and economic processes operate in order to ensure ecosystem goods and services valued by people are maintained. Building on the recognition of the need for greater interconnections between landscape ecology, socio-economics and policy, Spies et al. (2010) conclude that current ecosystem-based approaches to forest management in the Pacific North West region of the United States provide a good foundation for conserving biodiversity under climate change. However, this requires developing collaborative partnerships to promote adaptive management to deal with uncertainty and complexities.

People, culture and communities also matter. Landscape ecology cannot realize its full contribution to landscape sustainability without becoming more involved with the communities and landscape managers who live in and interact with landscapes. The special issue highlights the need for better knowledge exchange and participatory planning as a way of working towards the goal of sustainable landscapes. Bohnet (2010) presents a social-ecological planning framework for planning sustainable land and seascapes which recognizes the importance of peoplelandscape interactions and the need for greater knowledge integration from a variety of stakeholders. Her social-ecological framework provides opportunities for the community to engage in participatory planning and work towards a consensus of issues and joint development of strategies. Sherren et al. (2010) also recognise the importance of integration of scientific and community knowledge within a transdisciplinary approach to identifying sustainable pathways for rural landscapes. Their case study in rural New South Wales, Australia, investigates management options for building reciprocity between farming systems and ecosystems which is crucial in the context of global agricultural intensification. Both Sherren et al. (2010) and Bohnet (2010) highlight the challenges and tensions associated with building effective multiple stakeholder relationships. O'Farrell et al. (2010) continue along this theme by suggesting that it is important to consider the role of people in building sustainable landscapes by creating future economies and livelihoods that support sustainable use of ecosystem services. As a way of dealing with the challenges associated with knowledge integration, O'Farrell et al. (2010) suggest that it is essential to have a forum where scientists and stakeholders can interact to exchange knowledge.

Understanding complexity and detecting change

Landscapes function as complex adaptive systems in a constant state of change. Recognising and quantifying the multiple drivers of change and their interactions, including existing land-use pressures, plus emerging drivers of change (e.g., heat and moisture stress, altered fire regimes, new land use pressures) is an important challenge for landscape ecologists. If we are to adapt, modify behavior and rethink our landscape management practices to ensure sustainability in the future, it is important to question: Are there early signals of climate change impacting on landscapes? How can we detect these changes and attribute causal processes?

Bowman et al. (2010) focus on these questions, discussing how a landscape ecological approach can be used to separate the impacts of climate change on the tropical monsoon rainforests in Australia. Their study highlights the need for a rigorous landscape ecological methodology, including spatial and temporal analysis, for providing an historical context for understanding current and future change. Jones et al. (2010) continue with this theme by examining riparian ecosystems in the United States. They quantify the spatial and temporal pattern of change in riparian ecosystems in association with drivers of change and discuss the implications for critical ecosystem services that riparian zones provide. 
Managing and redesigning landscapes

for an uncertain future

Landscapes provide multiple functions and ecosystem services which often require quite different landscape configurations. Indentifying integrated landscape designs which can maintain these multiple functions and services is a major challenge for landscape ecology (Lovell and Johnston 2009). How do we redesign and restore landscapes for maintaining multiple functions and ecosystem services in a changing climate where the future is uncertain? Maintaining and restoring multiple landscape functions and ecosystems services are critical to sustainable landscapes and are mentioned in several of the papers in this special edition (O'Farrell et al. 2010; Ryan et al. 2010; Verboom et al. 2010).

Ryan et al. (2010) discuss the need to adapt semiarid agricultural landscapes to offset the risks associated with changes to water availability, climate and biodiversity under future global environmental change. They propose an integrated landscape design that maintains belts of native vegetation in the landscape, thereby preserving important landscape functions and ecosystem services whilst maintaining agricultural production. Verboom et al. (2010) also discuss the need to adapt landscape designs to buffer against climate change. They illustrate how landscape ecology can provide a framework for ensuring greater heterogeneity and connectivity to maintain viable fauna populations under climate change. They argue that adopting a landscape ecological approach to landscape redesign can be useful for collaborative planning needed for sustainable landscape management and can also provide opportunities for developing multifunctional landscapes.

\section{Closing remarks}

In summary, the papers in this special edition of Landscape Ecology present an insight into the role that landscape ecology can play in providing the scientific understanding of what is happening to the world's landscapes in response to global environmental change, mitigating some of its effects and working towards the goal of landscape sustainability. If landscape ecology is to be more effective in terms of contributing towards sustainability, there needs to be stronger emphasis put on bridging the gap between science and practice. This special edition presents some possible frameworks and tested approaches for achieving this. We hope that this edition will stimulate greater discussion amongst landscape ecologists on these important themes and encourage more research for advancing landscape ecology as a science able to rise to the challenges of global change we face this century.

Acknowledgments This special edition is an output from a symposium held at INTECOL 09 in Brisbane, Australia. We would like to thank all participants in the symposium, the researchers who contributed to the special edition and the reviewers who provided valuable comments and feedback in preparing these manuscripts for publication. We also would like to thank Jianguo $\mathrm{Wu}$ and others who made this special edition possible plus acknowledge Charles Darwin University and The University of Queensland for supporting the guest editors in this special edition.

\section{References}

Bowman DMJS, Murphy BP, Banfai DS (2010) Has global environmental change caused monsoon rainforests to expand in the Australian monsoon tropics? Landscape Ecol. doi:10.1007/s10980-010-9496-8

Bohnet IC (2010) Integrating social and ecological knowledge for planning sustainable land- and sea-scapes: experiences from the Great Barrier Reef region, Australia. Landscape Ecol. doi:10.1007/s10980-010-9504-z

Jones JB, Slonecker ET, Nash MS, Neale AC, Wade TG, Hamann S (2010) Riparian habitat changes across the continental United States (1972-2003) and potential implications for sustaining ecosystem services. Landscape Ecol. doi:10.1007/s10980-010-9510-1

Lovell ST, Johnston DM (2009) Creating multifunctional landscapes: how can the field of ecology inform the design of the landscape? Front Ecol Environ 7:212-220

McAlpine CA, Seabrook LM, Rhodes JR, Maron M, Smith C, Bowen ME, Butler SA, Powell O, Ryan JG, Fyfe CT, Adams-Hosking C, Smith A, Robertson O, Howes A, Cattarino L (2010) Can a problem-solving approach strengthen landscape ecology's contribution to sustainable landscape planning? Landscape Ecol. doi:10.1007/s10980010-9514-X

Musacchio LR (2009) The scientific basis for the design of landscape sustainability. Landscape Ecol 24:993-1013

Naveh Z (2007) Landscape ecology and sustainability. Landscape Ecol 22:1437-1440

O'Farrell PJ, Reyers B, Le Maitre DC, Milton SJ, Egoh B, Maherry A, Colvin C, Atkinson D, De Lange W, Blignaut JN, Cowling RM (2010) Multi-functional landscapes in semi arid environments: implications for biodiversity and ecosystem services. Landscape Ecol. doi:10.1007/s10980010-9495-9 
Pearson DM, Gorman JT (2010) Exploring the relevance of a landscape ecological paradigm for sustainable landscapes and livelihoods: a case application from the Northern Territory, Australia. Landscape Ecol. doi:10.1007/ s10980-010-9498-6

Ryan JG, McAlpine CA, Ludwig JA (2010) Integrated vegetation designs for enhancing water retention and recycling in agroecosystems. Landscape Ecol. doi:10.1007/s10980010-9509-7

Sherren K, Fischer J, Clayton H, Schirmer J, Dovers S (2010) Integration by case, place and process: transdisciplinary research for sustainable grazing in the Lachlan catchment, Australia. Landscape Ecol. doi:10.1007/s10980-010-9494-X

Spies TA, Giesen TG, Swanson FJ, Franklin JF, Lach D, Johnson KN (2010) Climate change adaptation strategies for federal forests of the Pacific northwest, USA: ecological, policy, and socio-economic perspectives. Landscape Ecol. doi:10.1007/s10980-010-9483-0

Termorshuizen JW, Opdam P, Van Den Brink A (2007) Incorporating ecological sustainability in landscape planning. Landsc Urban plan 79:374-384

Verboom J, Schippers P, Cormont A, Sterk M, Vos CC, Opdam PFM (2010) Population dynamics under increasing environmental variability: implications of climate change for ecological network design criteria. Landscape Ecol. doi: 10.1007/s10980-010-9497-7

Wu JG (2006) Landscape ecology, cross-disciplinarity, and sustainability science. Landscape Ecol 21:1-4 